\title{
Comparing the welfare of growing economies
}

\author{
Geir B. Asheim*
}

March 31, 2011

\begin{abstract}
Economies that currently have the same productive capacity may implement different growth rates. This entails that it is insufficient to base international comparisons of welfare solely on current well-being, or introducing the potential for future growth in an arbitrary manner. NNP-based measures trade off current well-being and the potential for future growth in a consistent manner. This paper shows that it matters for NNP-based measures whether different growth rates in different economies are due to different technological opportunities or different social preferences for development. The analysis illustrates the similarity between international comparisons of welfare and interpersonal comparisons of well-being.
\end{abstract}

Keywords and Phrases: National accounting, Growth, Dynamic welfare.

JEL Classification Numbers: D60, D90, O47.

${ }^{*}$ The paper is part of the research activities at the center of Equality, Social Organization, and Performance (ESOP) at the Department of Economics at the University of Oslo. ESOP is supported by the Research Council of Norway. I thank Marc Fleurbaey and two anonymous referees as well as Kjell Arne Brekke and participants at an ESOP seminar for helpful comments.

Address: Department of Economics, University of Oslo, P.O. Box 1095 Blindern, NO-0317 Oslo, Norway. Tel: +47 22855498 Fax: +47 22855035 Email: g.b.asheim@econ.uio.no 


\section{Introduction}

International comparisons of welfare are needed for laying a normative foundation for transfers between different economies. Such comparisons may also be useful for international negotiations on trade, debt relief and climate control, since agreements on such issues result in implicit transfers.

In order to perform international comparisons of welfare, one needs information on some notion of "per capita welfare" in economies that differ in many respects, including having different growth rates. This paper discusses how to use measures based on national accounting aggregates, in particular net national product (NNP), for such a purpose.

Economies that currently have the same productive capacity may implement different growth rates. This entails that it is insufficient to base international comparisons of welfare solely on current well-being, or introducing the potential for future growth in an arbitrary manner. An example in point is UNDP's Human Development Index (HDI). This index mixes measures of current well-being (consumption, health, education) with the potential for future development and growth (cf. Dasgupta, 2001, C1-C2). In particular, the only forward-looking component of the HDI is the gross investment part of gross domestic product (GDP), which makes no allowance for capital depreciation and resource depletion.

Fleurbaey and Gaulier (2009) present a careful welfare-economic analysis of how to correct per capita GDP for labor, risk of unemployment, health, household demography, inequalities and sustainability. However, they limit their analysis to the hypothetical case of a population permanently exposed to the current conditions, thereby abstracting from the problem addressed here.

The present paper contributes to the literature on welfare comparisons based on national accounting aggregates, in the tradition of Weitzman (1976). This literature has primarily been concerned with developing and applying the theory of national accounting to the question of making over-time welfare comparison within economies (see, e.g., Aronsson and Löfgren, 1993; Arrow et al., 2003a,b; Asheim, 2004; Asheim and Weitzman, 2001; Dasgupta and Mäler, 2000; Kemp and Long, 1982; Pezzey, 2004; Sefton and Weale, 2006). The problems addressed include how to make accounting comprehensive by allowing for environmental degradation and natural resource depletion as well as technological progress and population growth. Measures include growth in comprehensive NNP and a positive genuine savings indicator (a term coined by Hamilton, 1994, 
p. 166) measuring the value of changes in capital stocks. By calculating the genuine savings indicator for different countries, one can compare to what extent they take care of their own descendants. However, this is not welfare comparisons between different countries, an issue that has been scarcely treated in this line of literature (with Weitzman, 2001, and Asheim, 2010, being two exceptions).

The fact that the literature on national accounting aggregates has been concerned with over-time comparisons within economies, has naturally lead to a focus on the effects of changing productive capacity - as a result of investments, depletion and technological progress - while social preferences are assumed to remain unchanged through time. Usually, social preferences are taken to be of a discounted utilitarian type, where the economy maximizes the sum of discounted utilities, with both the discount rate and the instantaneous utility function being time-invariant.

On this background it is not surprising that - when the theory developed in this line of literature is applied to international comparison - it allows for different productive capacity and potential for growth, but assumes that different economies have identical social preferences. Indeed, this is what both Weitzman (2001) and Asheim (2010) do (see also Dasgupta and Mäler, 2000, Proposition 6).

In the present paper I allow for the possibility that different economies have different social preferences. I show that it matters for NNP-based measures whether different growth rates in different economies are due to different technological opportunities or different social preferences for development.

I keep my analysis as simple as possible, using a one-sector Ramsey-type growth model (to be presented in Section 2) as the vehicle for my arguments. In Section 3 I consider how to do international comparisons in the case where different growth rates are due to different technological constraints. With the same social preferences, the different sets of feasible consumption paths can be evaluated by their most preferred elements. The problem is how to compare the dynamic welfare associated with these most preferred elements by means of presently observable aggregates. I reproduce results showing that an adjusted measure of NNP can be used for such comparison.

In Section 4 I turn to the case where different growth rates are caused by different social preferences for development. If one adopts the position that economies are responsible for their social preferences but not for their technological opportunities, one obtains a clear ranking if the economies' sets of feasible consumption paths are nested. The sets of feasible consumption paths are nested if the economies have identical onesector technologies and, in this case, an unadjusted measure of NNP indicates which set 
is larger, as this measure is independent of social preferences. Hence, the result that NNP must be adjusted to make international comparisons is no longer applicable in the case with different social preferences and identical technologies. In Section 5 I discuss the significance of these observations, while in Section 6 I present concluding remarks.

\section{Model}

Consider a world with different economies, indexed $i=a, b$, etc., each with population equal to 1 . The analysis can easily be generalized to the case where different economies have populations of different size. Below I will comment on additional assumptions needed to interpret the variables and results on a per capita basis.

Denote by $c_{i}(t)$ the non-negative consumption in economy $i$ at time $t$. 'Consumption' should be interpreted as a scalar that indicates instantaneous well-being. No specific view on what constitutes instantaneous well-being is therefore implied by the subsequent analysis. Multiple consumption good models would allow for variation in preferences over consumption bundles, including differences in labor/leisure trade-offs. The simple one consumption good framework chosen here abstract from such variation in preferences between economies. It also means that international trade in consumption goods is not an essential part of the model, and that the interesting problem of making international comparisons of instantaneous well-being (e.g., by means of consumer price indices) is not addressed.

At each time $t$, net national product in terms of consumption (consumption-NNP) $y_{i}(t)$ in economy $i$ depends on the stock of capital $k_{i}(t)$ :

$$
y_{i}(t)=f_{i}\left(k_{i}(t)\right)
$$

The production function $f_{i}: \mathbb{R}_{+} \rightarrow \mathbb{R}_{+}$is twice continuously differentiable, with $f_{i}(0)=$ $0, f_{i}^{\prime}(k)>0$ and $f_{i}^{\prime \prime}(k)<0$ for all $k>0$, and $\lim _{k \rightarrow 0} f_{i}^{\prime}(k)=\infty$ and $\lim _{k \rightarrow \infty} f_{i}^{\prime}(k)=0$. 'Capital' should be interpreted as a scalar that indicates the stocks of different kinds of capital available to the economy, while 'consumption-NNP' should be interpreted as a scalar that indicates its productive capacity.

A consumption path $\{c(s)\}_{s=t}^{\infty}$ is feasible in economy $i$ at time $t$ if there exists a capital path $\{k(s)\}_{s=t}^{\infty}$ satisfying $k(t)=k_{i}(t)$ and, at each $s \geq t, f_{i}(k(s))=c(s)+$ $\dot{k}(s)$. In the case where two economies, $a$ and $b$, have the same technology $\left(f_{a}(\cdot)=\right.$ $f_{b}(\cdot)=f(\cdot)$ ), the assumption that capital is one-dimensional means that sets of feasible consumption paths are nested: The set of feasible consumption paths in economy $a$ is a 
subset of the set of feasible consumption paths in economy $b$ if and only if $k_{a}(t) \leq k_{b}(t)$, or equivalently, $f\left(k_{a}(t)\right) \leq f\left(k_{b}(t)\right)$ since $f(\cdot)$ is increasing.

Economy $i$ is assumed to implement a discounted utilitarian optimum. This means that, at each $t,\left\{c_{i}(s)\right\}_{s=t}^{\infty}$ maximizes

$$
\int_{t}^{\infty} u_{i}(c(s)) e^{-\rho_{i}(s-t)} d s
$$

over all feasible consumption paths, where the utility discount rate $\rho_{i}$ is positive and the instantaneous utility function $u_{i}: \mathbb{R}_{++} \rightarrow \mathbb{R}$ is twice continuously differentiable, with $u_{i}^{\prime}(c)>0$ and $u_{i}^{\prime \prime}(c)<0$ for all $c>0$, and $\lim _{c \rightarrow 0} u_{i}^{\prime}(c)=\infty$ and $\lim _{c \rightarrow \infty} u_{i}^{\prime}(c)=0$.

The analysis assumes that economies allocate their resources perfectly according to their discounted utilitarian objective. Hence, the interesting issue of performing welfare comparisons in economies with imperfect resource allocation mechanisms (see Arrow et al., 2003b) is not addressed here. Furthermore, it assumes that economies do not take into account that high growth rates leading to increased future welfare may result in obligations for assisting economies that experience lower growth rates.

Under the assumption that $k_{i}(0)>0$, standard analysis yields that $\left\{c_{i}(s)\right\}_{s=0}^{\infty}$ and $\left\{k_{i}(s)\right\}_{s=0}^{\infty}$ are interior paths satisfying, at each $t$,

$$
\begin{gathered}
u_{i}^{\prime}\left(c_{i}(t)\right)=Q_{i}(t), \\
f_{i}^{\prime}\left(k_{i}(t)\right)=\rho_{i}-\frac{\dot{Q}_{i}(t)}{Q_{i}(t)},
\end{gathered}
$$

where $Q_{i}(t)$ is the current value price of capital at time $t$ in terms of utility. Refer to $u_{i}\left(c_{i}(t)\right)+Q_{i}(t) \dot{k}_{i}(t)$ as the utility-NNP in economy $i$ at time $t$. The significance of utility-NNP was first pointed out by Weitzman (1976). If $u$ were linear, so that $u\left(c_{i}(t)\right)=$ $Q_{i}(t) c_{i}(t)$ by $(2)$, then utility-NNP would be proportional to consumption-NNP:

$$
u\left(c_{i}(t)\right)+Q_{i}(t) \dot{k}_{i}(t)=Q_{i}(t)\left(c_{i}(t)+\dot{k}_{i}(t)\right)=Q_{i}(t) f_{i}\left(k_{i}(t)\right)=Q_{i}(t) y_{i}(t) .
$$

Otherwise, as we will see, the choice between utility-NNP and consumption-NNP matters for welfare comparisons.

Fixing $\rho_{i}$ and $u_{i}$, the dynamic welfare of economy $i$ at time $t$ is an increasing function $w_{i}: \mathbb{R}_{++} \rightarrow \mathbb{R}$ of the capital stock $k_{i}(t)>0$ at time $t$, for given technology $f_{i}$ :

$$
w_{i}\left(k_{i}(t) ; f_{i}\right)=\int_{t}^{\infty} u_{i}\left(c_{i}(s)\right) e^{-\rho_{i}(s-t)} d s .
$$

This sets a simplified stage for asking the following question: What is the right concept for making welfare comparisons between different economies? Should we use consumption (or, equivalently, utility, since the $u$-function is increasing)? Or should we use consumption-NNP or utility-NNP? 


\section{Different technological opportunities}

Consider first the case where two economies, $a$ and $b$, have the same social preferences, in the sense that $u_{a}(\cdot)=u_{b}(\cdot)=u(\cdot)$ and $\rho_{a}=\rho_{b}=\rho$. Moreover, assume that the two economies have currently (at time 0 ) the same productive capacity, but different potential for growth. In particular, assume that $f_{a}(k)=k^{\alpha}$ and $f_{b}(k)=k^{\beta}$, with $\rho=\alpha<\beta$ and $k_{a}(0)=k_{b}(0)=1$. This implies that

$$
\begin{gathered}
f_{a}\left(k_{a}(0)\right)=1=f_{b}\left(k_{b}(0)\right), \\
\rho=\alpha=f_{a}^{\prime}\left(k_{a}(0)\right)<f_{b}^{\prime}\left(k_{b}(0)\right)=\beta .
\end{gathered}
$$

It now follows from (2) and (3), combined with a transversality condition, that

$$
\begin{array}{lll}
c_{a}(0)=f_{a}\left(k_{a}(0)\right)=1 & \text { and } & \dot{Q}_{a}(0)=0, \\
c_{b}(0)<f_{b}\left(k_{b}(0)\right)=1 & \text { and } & \dot{Q}_{b}(0)<0 .
\end{array}
$$

Since the rate of net productivity $f_{a}^{\prime}\left(k_{a}(0)\right)=\alpha$ in economy $a$ equals the rate of utility discount $\rho$, the optimal path in economy $a$ is to consume its consumption-NNP and keep capital constant. Hence, consumption and consumption-NNP will be kept equal to 1 at all times. The situation is different in economy $b$ where the rate of net productivity $f_{b}^{\prime}\left(k_{b}(0)\right)=\beta$ exceeds the rate of utility discount $\rho$. Here, the optimal path entails that only a fraction of its consumption-NNP is consumed, while the rest is used for capital accumulation. This leads to consumption and consumption-NNP growing from, respectively, $c_{b}(0)<1$ and $f_{b}\left(k_{b}(0)\right)=1$ towards $(\beta / \rho)^{\beta /(1-\beta)}>1$.

Which of these economies has higher welfare? First, note that the two economies are assumed to have identical social preferences, implying that they rank consumption paths in the same manner. Second, note that the optimal path in economy $a$, where consumption is kept constant at $c_{a}(t)=1$ is feasible in economy $b$, while the optimal path in economy $b$, where consumption grows from $c_{b}(t)<1$ initially to $c_{b}(t)>1$ eventually, is not feasible in economy $a$ due to its lower rate of net productivity. It follows directly from these facts that economy $a$ has lower welfare than economy $b$.

Two important conclusions follow from these observations.

(i) They are sufficient to rule out the use of instantaneous well-being, either in the form of consumption or utility, as a correct welfare index. The reason is that

$$
c_{a}(0)>c_{b}(0) \quad \text { and } \quad u\left(c_{a}(0)\right)>u\left(c_{b}(0)\right)
$$

hence, instantaneous well-being is higher in the economy with lower welfare. 
(ii) Consumption-NNP is not a correct welfare index, either. The reason is that

$$
y_{a}(0)=f_{a}\left(k_{a}(0)\right)=f_{b}\left(k_{b}(0)\right)=y_{b}(0)
$$

hence, consumption-NNP does not reflect that welfare is higher is economy $b$.

How then should we make welfare comparisons between the two economies? In particular, can national accounting aggregates be used to measure the maximized value of (1) in economy $a$ and $b$ ? Weitzman's (1976) seminal analysis implies that, for $i=a$, $b$,

$$
i \text { 's utility-NNP }=u\left(c_{i}(0)\right)+Q_{i}(0) \dot{k}_{i}(0)=\rho \int_{0}^{\infty} u\left(c_{i}(s)\right) e^{-\rho s} d s .
$$

This result means that utility-NNP, being the current value Hamiltonian for the economies' dynamic resource allocation problem, is proportional to dynamic welfare, where the common discount rate $\rho$ is the proportionality factor. Hence, utility-NNP provides a correct measurement of welfare in the case where the two economies have identical social preferences.

It follows from $(2)$ and the concavity of $u$ that $\left(c_{i}(0), \dot{k}_{i}(0)\right)$ maximizes $u(c(0))+$ $Q_{i}(0) \dot{k}(0)$ over all pairs $(c(0), \dot{k}(0))$ satisfying $c(0)+\dot{k}(0) \leq f_{i}\left(k_{i}(0)\right)$. Hence, if the optimal net investment at time $0, \dot{k}_{i}(0)$, does not equal zero, then the strict concavity of $u$ implies that utility-NNP and thus the welfare of economy $i$ exceed the welfare associated with holding consumption constant at $f_{i}\left(k_{i}(0)\right)$.

Above, we have considered an economy $b$ which due to its high potential for growth (since $\beta>\rho$ ) has positive optimal net investment at time 0 and therefore is better off than an economy $a$ which has zero optimal net investment at time 0 (since $\alpha=\rho$ ). In particular, with $\beta>\rho=\alpha$, economy $b$ has a greater potential for turning current consumption into capital for a given gain of future productive capacity (as $k^{\alpha}<k^{\beta}$ if $\alpha<\beta$ and $k>1$ ).

However, the same conclusion would be obtained if economy $b$ had a particularly low potential for growth (i.e., $\beta<\rho$ ), and thus negative optimal net investment at time 0 . It would be still be better off than economy $a$ given the shared discounted utilitarian social preferences. The reason that with $\beta<\rho=\alpha$, economy $b$ would have a greater potential for turning capital into current consumption for a given loss of future productive capacity (as $k^{\alpha}<k^{\beta}$ if $\alpha>\beta$ and $0<k<1$ ).

Of course, the result that utility-NNP is proportional to dynamic welfare does not depend on the assumption that the common utility discount rate equals one economy's rate of net productivity; this assumption has a purely pedagogical motivation as it 
ensures that one economy's optimal path exhibits zero growth. The result is also robust as that it generalizes beyond the one-sector model considered here to any stationary technology (in the sense that technological progress is captured by enhanced stocks). As long as the two economies maximize the same discount utilitarian objective function, utility-NNP can be used for international comparisons.

However, the result begs the following question: How can utility $u\left(c_{i}(0)\right)$ be measured from observable quantities and prices, and other information that might be available? In fact, Arrow, Dasgupta and Mäler have in a series of papers (Dasgupta and Mäler, 2000; Dasgupta, 2001; Arrow et al., 2003b) argued against the use of utility-NNP on the grounds that is not linear in prices and quantities and therefore difficult to measure. In particular, $u\left(c_{i}(0)\right)+Q_{i}(0) \dot{k}_{i}(0)$ need not equal $Q_{i}(0)\left(c_{i}(0)+\dot{k}_{i}(0)\right)=Q_{i}(0) f_{i}\left(k_{i}(0)\right)=Q_{i}(0) y_{i}(0)$ due to the strict concavity of $u$. Weitzman (2001) has contributed to a solution of this problem by pointing out that $u\left(c_{i}(0)\right)-Q_{i}(0) c_{i}(0)$ is a consumer surplus term which in principle is measurable.

In the case where economies $a$ and $b$ have different, but time-invariant, population sizes, the results of the present section can be given a per capita interpretation without further assumptions. I discuss in Asheim (2010, Section 4) the significance of Weitzman's (2001) consumer surplus term in a context where economies have different population sizes.

\section{Different social preferences for development}

Consider next the case where two economies, $a$ and $b$, have the same productive capacity and the same potential for growth, in the sense that $k_{a}(0)=k_{b}(0)=k(0)$ and $f_{a}(\cdot)=$ $f_{b}(\cdot)=f(\cdot)$. Assume also that economies $a$ and $b$ have the same instantaneous utility function: $u_{a}(\cdot)=u_{b}(\cdot)=u(\cdot)$. However, assume now that they have different social preferences in the sense that $f^{\prime}(k(0))=\rho_{a}>\rho_{b}>0$. Hence,

$$
\begin{gathered}
f_{a}\left(k_{a}(0)\right)=f(k(0))=f_{b}\left(k_{b}(0)\right), \\
\rho_{a}=f_{a}^{\prime}\left(k_{a}(0)\right)=f^{\prime}(k(0))=f_{b}^{\prime}\left(k_{b}(0)\right)>\rho_{b} .
\end{gathered}
$$

It now follows from (2) and (3), combined with a transversality condition, that

$$
\begin{array}{lll}
c_{a}(0)=f_{a}\left(k_{a}(0)\right)=f(k(0)) & \text { and } & \dot{Q}_{a}(0)=0, \\
c_{b}(0)<f_{b}\left(k_{b}(0)\right)=f(k(0)) & \text { and } \quad & \dot{Q}_{b}(0)<0 .
\end{array}
$$


Since the rate of net productivity $f_{a}^{\prime}\left(k_{a}(0)\right)=f^{\prime}(k(0))$ in economy a equals its rate of utility discount $\rho_{a}$, the optimal path in economy $a$ is to consume its consumption-NNP and keep capital constant. Hence, consumption and consumption-NNP will be kept equal to $f(k(0))$ at all times. The situation is different in economy $b$ where the rate of net productivity $f_{b}^{\prime}\left(k_{b}(0)\right)=f^{\prime}(k(0))$ exceeds its rate of utility discount $\rho_{b}$. Here, the optimal path entails that only a fraction of its consumption-NNP is consumed, while the rest is used for capital accumulation. This leads to consumption and consumption-NNP growing from, respectively, $c_{b}(0)<f(k(0))$ and $f_{b}\left(k_{b}(0)\right)=f(k(0))$ towards some common level, $f(k(\infty))$, exceeding $f(k(0))$, where $k(\infty)$ is determined by $f^{\prime}(k(\infty))=\rho_{b}$.

In this case, which economy has higher welfare? Since the two economies are assumed to have the same productive capacity and the same potential for growth, they have identical sets of feasible consumption paths. Moreover, since in each economy the optimal path is unique, economy $a$ according to its social preferences strictly prefers $\left\{c_{a}(s)\right\}_{s=0}^{\infty}$ to $\left\{c_{b}(s)\right\}_{s=0}^{\infty}$, while economy $b$ has the opposite ranking.

One possibility is to adopt the position that economies are responsible for their social preferences but not for their technological opportunities. The underlying intuition for this might be debatable: it is not completely clear that economies are responsible for their preferences, because sociological or political issues may be the source of economies' apparent impatience. Anyway, the position leads to the conclusion that the two economies are equally well off, given that their sets of feasible consumption paths are identical. This conclusion is reached by basing the welfare comparisons on consumption-NNP, as both economies' consumption-NNP at time 0 equals $f(k(0))$.

Building on this position, one can conclude as follows:

(i) Instantaneous well-being, either in the form of consumption or utility, is not a correct welfare index, even in the present case where different growth rates are caused by different social preferences for development. The reason is that

$$
c_{a}(0)>c_{b}(0) \quad \text { and } \quad u\left(c_{a}(0)\right)>u\left(c_{b}(0)\right)
$$

hence, instantaneous well-being is higher in the economy with lower growth.

(ii) Utility-NNP is not a correct welfare index, either. The reason is that

$$
a \text { 's utility-NNP }=u\left(c_{a}(0)\right)<u\left(c_{b}(0)\right)+Q_{b}(0) \dot{k}_{b}(0)=b \text { 's utility-NNP }
$$

since $\left(c_{b}(0), \dot{k}_{b}(0)\right)$ uniquely maximizes $u(c(0))+Q_{b}(0) \dot{k}(0)$ over all pairs $(c(0)$, $\dot{k}(0))$ satisfying $c(0)+\dot{k}(0) \leq f(k(0))=c_{a}(0)$. Hence, utility-NNP does not reflect that the two economies have the same set of feasible consumption paths. 
As noted in Section 2, the sets of feasible consumption paths at time 0 are nested if the two economies have the same one-sector technology: the set of feasible consumption paths in economy $a$ is a subset of the set of feasible consumption paths in economy $b$ set if and only if $k_{a}(0) \leq k_{b}(0)$, or equivalently,

$$
a \text { 's consumption-NNP }=y_{a}(0)=f\left(k_{a}(0)\right) \leq f\left(k_{b}(0)\right)=y_{b}(0)=b \text { 's consumption-NNP }
$$

since $f(\cdot)$ is increasing. Therefore, consumption-NNP can be used for welfare comparison between economies with different social preferences as long as their one-sector technologies are identical. This result does not carry over to multiple capital good models like the Dasgupta-Heal-Solow model (Dasgupta and Heal, 1974; Solow, 1974) of capital accumulation and resource depletion - where the sets of a feasible consumption paths need not be nested according to their consumption-NNP, even if their technologies are identical.

In the case where economies $a$ and $b$ have different, but time-invariant, population sizes, the results of the present section can be given a per capita interpretation provided that $f(k):=F(k, 1)$, where $F: \mathbb{R}_{+}^{2} \rightarrow \mathbb{R}_{+}$is a constant-returns-to-scale production function of total capital, $K$, and total labor, $L$ (= population), and where $k:=K / L$ is the per capita capital stock. Under this assumption on $F$, per capita production possibilities will be independent of scale.

\section{Discussion}

Let $f_{z}$ be a reference technology in the class considered in Section 2, satisfying the additional assumption that $\lim _{k \rightarrow \infty} f_{z}(k)=\infty$. In particular, any technology of the form $k^{\zeta}$ with $\zeta>0$ is in this restricted class. Then, for any economy $i$ and each time $t$, there exists a unique $k^{*}>0$ such that maximized dynamic welfare under technology $f_{z}$ with $k(t)=k^{*}$ equals the actual dynamic welfare of economy $i$ at time $t$ :

$$
w_{i}\left(k^{*} ; f_{z}\right)=w_{i}\left(k_{i}(t) ; f_{i}\right),
$$

where the function $w_{i}$ is defined in equation (4). Note that $f_{z}\left(k^{*}\right)$ does not exceed the stationary equivalent consumption $u_{i}^{-1}\left(\rho_{i} w_{i}\left(k_{i}(t) ; f_{i}\right)\right)$; this ensures existence under the assumption that $f_{z}$ is unbounded, while the property that $w_{i}$ is increasing implies uniqueness. Define the $f_{z}$-equivalent consumption-NNP in economy $i$ at time $t$ by $^{1}$

$$
y_{i}\left(t ; f_{z}\right)=f_{z}\left(k^{*}\right) .
$$

\footnotetext{
${ }^{1}$ This kind of measure was suggested by a referee. I am grateful for his/her constructive comment.
} 
It follows from these definitions that, for any economy $i$ and each time $t$, the $f_{i^{-}}$ equivalent consumption-NNP equals economy $i$ 's actual consumption-NNP at time $t$ :

$$
y_{i}\left(t ; f_{i}\right)=f_{i}\left(k_{i}(t)\right)=y_{i}(t) .
$$

The key point here is to allow economies to be responsible for their preferences: paths are evaluated using actual preferences for development. However, the use of a reference technology which may be different from the one available to them means that they are not responsible for their technologies.

The $f_{z}$-equivalent consumption-NNP has the attractive property that it is a single measure that can be used for international comparisons of dynamic welfare in both cases considered in Sections 3 and 4. In the case treated in Section 3, with different technological opportunities and identical social preferences, choose $f_{z}=f_{a}$. Then the equality $w_{i}\left(k^{*} ; f_{a}\right)=w_{i}\left(1 ; f_{b}\right)$ is satisfied for $k^{*}>1$ as the dynamic welfare of economy $b$ exceeds that which would have been feasible with initial capital stock equal to 1 under technology $f_{a}$. Hence, $y_{a}\left(0 ; f_{a}\right)=f_{a}(1)<f_{a}\left(k^{*}\right)=y_{b}\left(0 ; f_{a}\right)$, which provides a correct ranking of dynamic welfare. Likewise, choosing $f_{z}=f_{b}$ would have given $y_{a}\left(0 ; f_{b}\right)<$ $f_{b}(1)=y_{b}\left(0 ; f_{b}\right)$, showing that the ranking does not depend on which technology is used as reference. In the case treated in Section 4, with identical technological opportunities and different social preferences, choose $f_{z}=f=f_{a}=f_{b}$. Then trivially, $y_{a}(0 ; f)=$ $f(1)=y_{b}(0 ; f)$, which provides a correct ranking of dynamic welfare also in this case.

However, there are two problems with $f_{z}$-equivalent consumption-NNP. The first problem is that it is not expressed in terms of presently observable national accounting aggregates, and an attempt to produce an empirical estimate of this measure would be informationally demanding. Instead of being based solely on the current productive capacity, it requires knowledge of the entire future consumption path. The second problem is that the ranking in international comparisons where both technological opportunities and social preferences differ may depend on which technology is used as reference. A simple example will illustrate how such indeterminacy may arise.

In this example, consider the case where two economies, $a$ and $b$, have currently (at time 0) the same productive capacity, but different potential for growth. In particular, assume that $f_{a}(k)=k^{\alpha}$ and $f_{b}(k)=k^{\beta}$, with $\alpha>\beta>0$ and $k_{a}(0)=k_{b}(0)=1$. Assume also that economies $a$ and $b$ have the same instantaneous utility function, $u_{a}(\cdot)=u_{b}(\cdot)=u(\cdot)$, but different utility discount rates, $\rho_{a}=\alpha>\beta=\rho_{b}$. Hence,

$$
\begin{gathered}
f_{a}\left(k_{a}(0)\right)=1=f_{b}\left(k_{b}(0)\right), \\
\rho_{a}=f_{a}^{\prime}\left(k_{a}(0)\right)>f_{b}^{\prime}\left(k_{b}(0)\right)=\rho_{b} .
\end{gathered}
$$


It now follows from (2) and (3), combined with a transversality condition, that

$$
\begin{array}{lll}
c_{a}(0)=f_{a}\left(k_{a}(0)\right)=1 & \text { and } & \dot{Q}_{a}(0)=0 \\
c_{b}(0)=f_{b}\left(k_{b}(0)\right)=1 & \text { and } & \dot{Q}_{b}(0)=0
\end{array}
$$

since in each economy the rate of net productivity equals its utility discount rate.

To illustrate the problems associated with comparing the dynamic welfare of economies $a$ and $b$, construct two hypothetical economies, $c$ and $d$, where economy $c$ has $a$ 's social preferences and $b$ 's technological opportunities $\left(\rho_{c}=\rho_{a}\right.$ and $f_{c}(k)=k^{\beta}$ with $\left.k_{c}(0)=1\right)$, while economy $d$ has $b$ 's social preferences and $a$ 's technological opportunities $\left(\rho_{d}=\rho_{b}\right.$ and $f_{d}(k)=k^{\alpha}$ with $\left.k_{d}(0)=1\right)$. Hence,

$$
\begin{gathered}
f_{c}\left(k_{c}(0)\right)=1=f_{d}\left(k_{d}(0)\right), \\
\rho_{c}=f_{d}^{\prime}\left(k_{d}(0)\right)>f_{c}^{\prime}\left(k_{c}(0)\right)=\rho_{d} .
\end{gathered}
$$

Again, applying (2) and (3), combined with a transversality condition, yield

$$
\begin{aligned}
& c_{c}(0)>f_{c}\left(k_{c}(0)\right)=1 \quad \text { and } \quad \dot{Q}_{c}(0)>0, \\
& c_{d}(0)<f_{d}\left(k_{d}(0)\right)=1 \quad \text { and } \quad \dot{Q}_{d}(0)<0,
\end{aligned}
$$

since in economy $c$ the rate of net productivity falls short of its utility discount rate, while in economy $d$ it is the other way around.

The optimal path in economy $a$, where consumption is kept constant at $c_{a}(t)=1$ is feasible in economy $c$, while the optimal path in economy $c$, where consumption declines from $c_{c}(t)>1$ initially to $c_{c}(t)<1$ eventually, is not feasible in economy $a$ due to its higher rate of net productivity. It follows directly from these facts that economy $a$ has lower welfare than economy $c$ since these economies have the same social preferences. However, economies $c$ and $b$, which have different social preferences for development, are equally well off as they have the same technological opportunities. These conclusions can be summarized in terms of the $f_{b}$-equivalent consumption-NNP:

$$
y_{a}\left(0 ; f_{b}\right)<y_{c}\left(0 ; f_{b}\right)=y_{b}\left(0 ; f_{b}\right) .
$$

Likewise, the optimal path in economy $b$, where consumption is kept constant at $c_{b}(t)=1$ is feasible in economy $d$, while the optimal path in economy $d$, where consumption grows from $c_{d}(t)<1$ initially to $c_{d}(t)>1$ eventually, is not feasible in economy $b$ due to its lower rate of net productivity. It follows directly from these facts that economy $b$ has lower welfare than economy $d$ since these economies have the same social 
preferences. However, economies $d$ and $a$, which have different social preferences for development, are equally well off as they have the same technological opportunities. These conclusions can be summarized in terms of the $f_{a}$-equivalent consumption-NNP:

$$
y_{b}\left(0 ; f_{a}\right)<y_{d}\left(0 ; f_{a}\right)=y_{a}\left(0 ; f_{a}\right) .
$$

Expressions (5) and (6) reach opposite conclusions concerning the welfare ranking of economies $a$ and $b$, which differ both in terms of technological opportunities and social preferences for development. Essentially, economy $a$ envies the technological opportunities of economy $b$, while economy $b$ envies the technological opportunities of economy $a$. As this phenomenon is well-known in the allocation of private consumption goods among different individuals, it illustrates the similarity between international comparisons of dynamic welfare and interpersonal comparisons of well-being. In both cases, comparable information about preferences appears to be needed.

In the present paper I have been concerned with answering the question: Which of two economies has higher dynamic welfare? Even though the above example illustrates the problems associated with answering this question, it is still of interest to go further and ask: Does a redistribution of technological opportunities lead to a better social state from supranational perspective? The insights provided by work of Fleurbaey and Maniquet $(2005,2008)$ on fair social orderings of private good allocations, showing that it is possible to construct social orderings which depend only on ordinal non-comparable information about preferences, are applicable also in the present setting. However, such application is beyond the scope of the present paper.

\section{Concluding remarks}

On the basis of the simplified analysis of the present paper, it follows that instantaneous well-being cannot be used for international comparisons of welfare between economies with different growth rates. Provided that one accepts the assumption that the compared economies maximize welfare, this conclusion holds independently of what specific conception on instantaneous well-being one adopts.

In the polar cases, where either social preferences are identical, so that different sets of feasible consumption paths can be evaluated by their most preferred elements, or technological constraints are identical, so that different sets of feasible consumption paths are nested and can be evaluated by set inclusion, clear conclusions can be reached. In particular, the analysis illustrates how utility-NNP as proposed by Weitzman (1976) is applicable if the different growth rates are due to different technological 
opportunities and not different social preferences for development. Moreover, it suggests that consumption-NNP yields a more reasonable conclusion if the situation is the opposite; when the different growth rates are due to different social preferences for development rather than different technological opportunities. However, the hybrid situation, where both technological constraints and social preferences are different, is more complicated and international comparison of dynamic welfare without comparable information about preferences seems problematic.

Real-world measurement of national product has many deficiencies. Per capita consumption, as measured, may for various reasons not correspond to instantaneous well-being. Moreover, the measurement of national product may not incorporate adequate allowance for capital depreciation and resource depletion, and may not account for technological progress.

It follows from the theory of national accounting in the tradition of Weitzman (1976) that utility-NNP, not consumption-NNP, has welfare significance when making welfare comparisons between different economies. As shown by Weitzman (2001), this means that national product has to be subject also to a consumer surplus adjustment. The analysis of the present paper suggests that this latter adjustment may not be appropriate if different growth rates are due to different social preferences rather than different technological opportunities.

It is an empirical question whether variation in growth rates between different economies are caused by the weight they place on future prospects rather than their ability to turn current savings into increased future productivity. If the process of globalization has disseminated technological knowledge without eliminating cultural differences, then the analysis of this paper suggests that a comprehensive measure of consumption-NNP may serve as a better indicator for welfare than the theory of national accounting has lead us to believe.

When moving beyond the simple framework in which the present analysis has been performed, it is, however, an open problem to investigate how to compare the welfare of growing economies in the case where divergence in growth rates is due to differences in social preferences for development. In particular, with multiple capital goods, it does not hold that set of feasible consumption paths in different economies are nested according to the value of their consumption-NNP. The complications are magnified within a multiple consumption-good setting where economies also differ in their preferences over consumption bundles, and within a setting where economies also differ in their technological constraints. 


\section{References}

Aronsson, T. and Löfgren, K.-G. (1993), Welfare consequences of technological and environmental externalities in the Ramsey growth model, Natural Resource Modeling 7, 1-14.

Arrow, K., Dasgupta, P.S., and Mäler, K.-G. (2003a), The genuine savings criterion and the value of population, Economic Theory 21, 217-225.

Arrow, K., Dasgupta, P.S., and Mäler, K.-G. (2003b), Evaluating projects and assessing sustainable development in imperfect economies, Environmental and Resource Economics 26, 647-685.

Asheim, G.B. (2004), Green national accounting with a changing population, Economic Theory 23, 601-619.

Asheim, G.B. (2010), Global welfare comparisons, Canadian Journal of Economics 43, 14121432.

Asheim, G.B. and Weitzman, M. (2001), Does NNP growth indicate welfare improvement?, Economics Letters 73, 233-239.

Dasgupta, P.S. (2001), Valuing objects and evaluating policies in imperfect economies, Economic Journal 111, C1-C29.

Dasgupta, P.S. and Heal, G. (1974), The optimal depletion of exhaustible resources, Review of Economic Studies 41, Symposium on the Economics of Exhaustible Resources, 3-28.

Dasgupta, P.S. and Mäler, K.-G. (2000), Net national product, wealth, and social well-being, Environment and Development Economics 5, 69-93.

Fleurbaey, M. and Gaulier, G. (2009), International comparisons of living standards by equivalent incomes, Scandinavian Journal of Economics 111, 597-624.

Fleurbaey, M. and Maniquet, F. (2005), Fair social orderings when agents have unequal production skills, Social Choice and Welfare 24, 93-127.

Fleurbaey, M. and Maniquet, F. (2008), Fair social orderings, Economic Theory 34, 25-45.

Hamilton, K. (1994), Green adjustments to GDP, Resources Policy 20, 155-168.

Kemp, M.C. and Long, N.V. (1982), On the evaluation of social income in a dynamic economy: Variations on a Samuelsonian theme, in G.R. Feiwel (ed.), Samuelson and Neoclassical Economics, Kluwer Academic Press, Dordrecht.

Pezzey, J. (2004), One-sided sustainability tests with amenities, and changes in technology, trade and population, Journal of Environment Economics and Management 48, 613-631. 
Sefton, J.A. and Weale, M.R. (2006), The concept of income in a general equilibrium, Review of Economic Studies 73, 219-249.

Solow, R.M. (1974), Intergenerational Equity and Exhaustible Resources, Review of Economic Studies 41, Symposium on the economics of exhaustible resources, 29-45.

Weitzman, M.L. (1976), On the welfare significance of national product in a dynamic economy, Quarterly Journal of Economics 90, pp. 156-162.

Weitzman, M.L. (2001), A contribution to the theory of welfare accounting, Scandinavian Journal of Economics 103, pp. 1-23. 